\title{
An Analytical Electron Microscopy Study of the Initial Stage of Formation Processes of Aged Omega Phase Crystals in a Ti-15Mo Alloy due to Aging at 323 K.
}

\author{
H. Matsumoto*, E. Sukedai** and H. Hashimoto** \\ * Graduate school, Okayama University of Science, Okayama 700-0005, Japan. \\ ** Faculty of Engineering,, Okayama University of Science, Okayama 700-0005, Japan.
}

Formation processes of aged omega phase crystals in beta Titanium alloys have been investigated by sever al methods, for instance, measuring contents of solute atoms in aged omega phase crystals. Hickman report ed that Mo contents in aged omega phase crystals in a Ti-8at\%Mo alloy aged at $573 \mathrm{~K}$ for $3.6 \mathrm{ks}$ were lower than those of the matrix[1]. However, the initial stage of formation processes has not been clarified. As a reason, aged omega phase particles at the initial stage are so small that it was difficult to measure composi tions in aged omega phase crystals. Recently, an analytical electron microscope, on which an EDS system and a high brightness source of a field emission gun are equipped, has been developed. The microscope enables to analyze compositions of nm-region of materials, and it becomes possible to analyze composi tions in aged omega phase particles at the initial stage. Therefore, the results obtained using this equipment are useful for considering initial stage of formation processes of aged omega phase crystals due to aging. In the present work, in order to get a knowledge on the initial stage of formation processes of aged omega phase crystals, the change of Mo contents in omega phase crystals in a Ti-15Mo alloy due to aging at $323 \mathrm{~K}$ was investigated using an analytical electron microscopy method.

A Ti-15Mo (mass\%) alloy was solution-treated at $1073 \mathrm{~K}$ for $3.6 \mathrm{ks}$ in a vacuum, then quenched by ice water in a vacuum. A thin foil specimen was prepared by an electron polishing method. An electron-micro scope, JEM 2010F (JEOL) operated at $200 \mathrm{kV}$ was used. Aging at $323 \mathrm{~K}$ was carried out using a specimen heating stage with double tilting axes, EM-31030 (JEOL). Composition analysis of omega phase crystals and the matrices around them were carried out using an EDS system of NORAN INSTRUMENT, and the probe size was approximately $1 \mathrm{~nm}$ and live-time was $50 \mathrm{sec}$. In-situ dark field image observations were also carried out using the same diffraction spot of one omega phase variant crystals with an incident beam parallel to $\langle 110\rangle$ direction of the matrix. All images were recorded on imaging plates (FDL-UR-V).

Fig. 1(a) and (b) show dark field images taken from the same area of a specimen as-quenched and aged at $323 \mathrm{~K}$ for $36 \mathrm{ks}$, respectively. White arrows in each image indicate the same omega phase crystal. In Fig.1 (a), as-quenched omega phase crystals with approximately $3.5 \mathrm{~nm}$ in diameter can be seen. In Fig.1 (b), the size of omega phase crystals increases. Therefore, it is found that aged omega phase crystals are formed after aging for $36 \mathrm{ks}$. However, an aging period for aged omega phase crystals to be formed is not clear. In order to clarify the period, EDS analyses and in-situ dark field observations were carried out at $7.2 \mathrm{ks}$ each until $21.6 \mathrm{ks}$, then at $3.6 \mathrm{ks}$ each until $36 \mathrm{ks}$. Table 1 shows the results of EDS analysis from an as-quenched state to an aged state for $36 \mathrm{ks}$. Mo contents obtained from each omega phase crystal were indicated by intensity ratios of Mo-K alpha to Ti-K alpha in EDX spectra of each omega phase crystal. In the case of asquenched state, Mo contents in as-quenched omega crystals were almost the same as those of the matrices around them. This tendency continued until $21.6 \mathrm{ks}$. However, differences of Mo contents between omega phase crystals and the matrices were recognized after aged for $25.2 \mathrm{ks}$. And the differences were increased from $25.2 \mathrm{ks}$ to $36.0 \mathrm{ks}$ continuously. Therefore, it is considered that the formation of aged omega phase crystals begins at the aging for $25.2 \mathrm{ks}$ at $323 \mathrm{~K}$, and that Mo contents in aged omega phase crystal become more and more decrease as aging time increase.

\section{References}

[1] B. S. Hickman: Trans. Metall. Soc. AIME, 245 (1969) 1329-1336. 


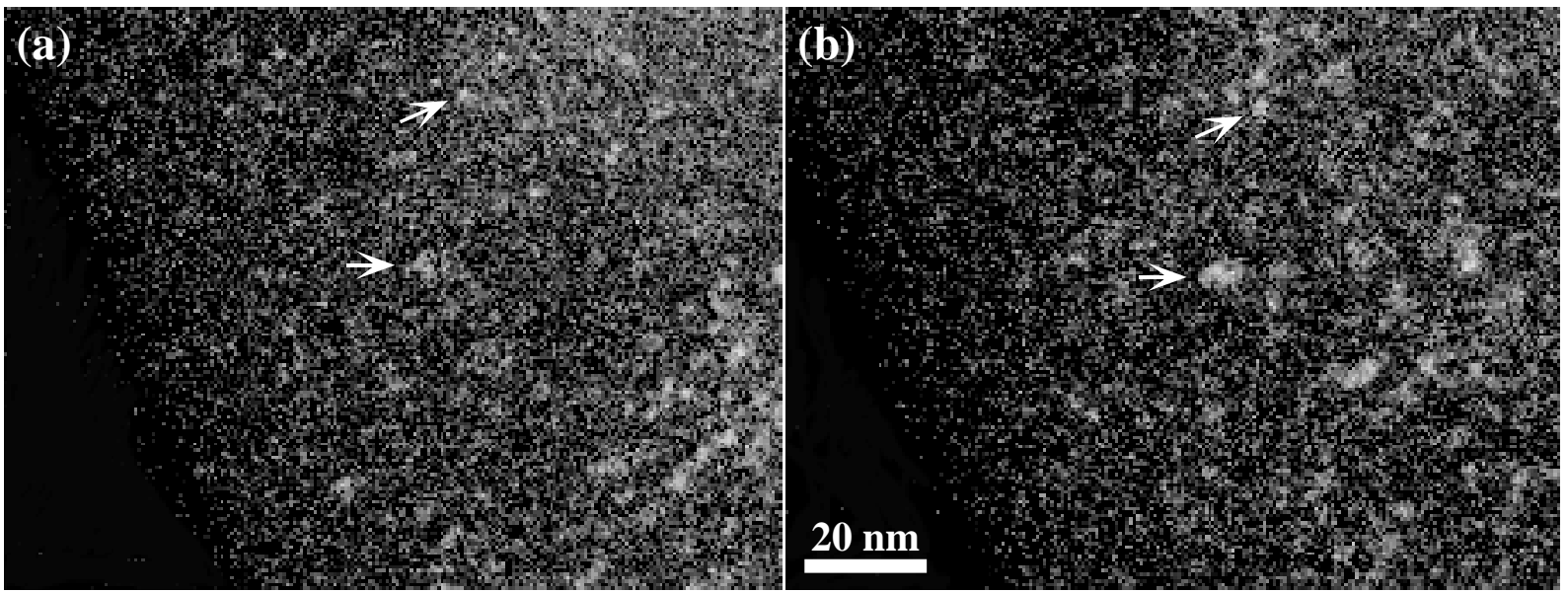

Fig. 1 In-situ dark field images of $\omega$ phase crystals of a Ti-15mass\%Mo alloy using the same diffraction spot of one $\omega$ phase variant crystals: (a) as-quenched state, (b) aged at $323 \mathrm{~K}$ for $36 \mathrm{ks}$. Incident beams were parallel to $<110>\beta$. A white allow indicate same $\omega$ phase particle.

Table 1 Intensity ratios of Mo-k $\alpha$ to Ti-k $\alpha$ in EDX spectra from $\omega$-phase crystals and the matrices of a Ti-15Mo alloy as-quenched state, and aged at $323 \mathrm{~K}$ for $7.2 \mathrm{ks}-36 \mathrm{ks}$. Each results were measured from the same specimen.

\begin{tabular}{|c|c|c|c|c|c|c|c|c|c|}
\hline \multirow{2}{*}{ Heat treatments } & \multirow{2}{*}{ Phases } & \multicolumn{8}{|c|}{ Places } \\
\hline & & 1 & 2 & 3 & 4 & 5 & 6 & 7 & 8 \\
\hline \multirow{2}{*}{ As-quenched } & $\omega$ & 0.098 & 0.098 & 0.106 & 0.102 & 0.105 & 0.105 & 0.096 & 0.109 \\
\hline & matrix & 0.095 & 0.102 & 0.102 & 0.097 & 0.097 & 0.097 & 0.095 & 0.102 \\
\hline \multirow{2}{*}{ Aged for $7.2 \mathrm{ks}$ at $323 \mathrm{~K}$} & $\omega$ & 0.089 & 0.103 & 0.093 & 0.089 & 0.101 & 0.101 & 0.090 & 0.105 \\
\hline & matrix & 0.099 & 0.076 & 0.092 & 0.099 & 0.094 & 0.094 & 0.095 & 0.104 \\
\hline \multirow{2}{*}{ Aged for $14.4 \mathrm{ks}$} & $\omega$ & 0.078 & 0.084 & 0.076 & 0.074 & 0.085 & 0.085 & 0.083 & 0.085 \\
\hline & matrix & 0.096 & 0.088 & 0.074 & 0.081 & 0.074 & 0.074 & 0.085 & 0.090 \\
\hline \multirow{2}{*}{ Aged for $21.6 \mathrm{ks}$} & $\omega$ & 0.087 & 0.084 & 0.090 & 0.082 & 0.086 & 0.086 & 0.098 & 0.109 \\
\hline & matrix & 0.093 & 0.093 & 0.098 & 0.079 & 0.079 & 0.079 & 0.094 & 0.089 \\
\hline \multirow{2}{*}{ Aged for $25.2 \mathrm{ks}$} & $\omega$ & 0.111 & 0.093 & 0.098 & 0.106 & 0.096 & 0.096 & 0.098 & 0.101 \\
\hline & matrix & 0.098 & 0.093 & 0.099 & 0.093 & 0.100 & 0.100 & 0.109 & 0.102 \\
\hline \multirow{2}{*}{ Aged for $28.8 \mathrm{ks}$} & $\omega$ & 0.114 & 0.109 & 0.104 & 0.111 & 0.110 & 0.110 & 0.115 & 0.104 \\
\hline & matrix & 0.114 & 0.106 & 0.104 & 0.121 & 0.111 & 0.111 & 0.120 & 0.111 \\
\hline \multirow{2}{*}{ Aged for $32.4 \mathrm{ks}$} & $\omega$ & 0.110 & 0.109 & 0.110 & 0.109 & 0.096 & 0.096 & 0.089 & 0.088 \\
\hline & matrix & 0.117 & 0.107 & 0.106 & 0.113 & 0.102 & 0.102 & 0.101 & 0.115 \\
\hline \multirow{2}{*}{ Aged for $36.0 \mathrm{ks}$} & $\omega$ & 0.103 & 0.109 & 0.097 & 0.109 & 0.081 & 0.081 & 0.083 & 0.084 \\
\hline & matrix & 0.134 & 0.114 & 0.111 & 0.100 & 0.121 & 0.121 & 0.118 & 0.127 \\
\hline
\end{tabular}

